Educación Física y Ciencia, vol. 22, nº, e145, octubre-diciembre 2020. ISSN 2314-2561

Universidad Nacional de La Plata.

Facultad de Humanidades y Ciencias de la Educación.

Departamento de Educación Física

\title{
Políticas Públicas de Gênero para a Educação e a Educação Física no Brasil, na Argentina e no Uruguai
}

Public Gender Policies for Education and Physical Education in Brazil, Argentina and Uruguay

Erineusa Maria da Silva erineusams@yahoo.com.br Centro de Educação Física e Desportos (CEFD) da Universidade Federal do Espirito Santo (UFES), Brasil

https://orcid.org/0000-0002-8736-6739

Ileana Wenetz

ilewenetz@gmail.com Centro de Educação Física e Desportos (CEFD) da Universidade Federal do Espirito Santo (UFES), Brasil Jose Manuel Alvarez Seara josmanu3@gmail.com Instituto Superior de Educación Física, Centro Universitario Regional Este, Universidad de la República, Uruguay https://orcid.org/0000-0002-6987-7893

Pablo Ariel Scharagrodsky pas@unq.edu.ar

Universidad Nacional de La Plata. Universidad de Quilmes, Argentina

Recepção: 06 Maio 2020 Aprovação: 05 Outubro 2020 Publicação: 09 Outubro 2020

Cita sugerida: Silva, E. M. da, Wenetz, I., Alvarez Seara, J. M. y Scharagrodsky, P. A. (2020). Políticas Públicas de Gênero para a Educação e a Educação Física no Brasil, na Argentina e no Uruguai. Educación Física y Ciencia, 22(4), e145. https://doi.org/10.24215/23142561e145 https://orcid.org/pas@unq.edu.ar

Resumo: O objetivo é analisar as políticas públicas de gênero na educação no Brasil, na Argentina e no Uruguai e, apresentar o percurso de criação dessas políticas nos três países, delinear trajetórias comuns e não comuns, conforme suas conjunturas específicas, bem como sua adoção/aplicação/interferência no campo da Educação Física. Este estudo comparativo, qualitativo, utilizou-se da revisão documental, de documentos oficiais e de matérias publicadas em jornais e sites para a coleta de dados referentes ao último quartel do século XX e primeiro do século XXI. Nas análises, apoiamo-nos em estudos feministas, de gênero e em políticas públicas. Concluímos que, embora a Argentina e o Uruguai se tenham antecipado ao Brasil na formulação de legislações para o enfrentamento da discriminação de gênero e sexo, os três países continuam a enfrentar dificuldades na implementação e efetivação dessas políticas nas duas áreas, especialmente na atualidade, tendo em vista a resistência de setores conservadores.

Palavras-chave: Políticas públicas em educação, Gênero e educação, Política comparada na América do Sul.

Abstract: The objective of this article is to analyze public gender policies in education in Brazil, Argentina and Uruguay, present in the path of creation of these policies in the three countries, with a view to delineating common trajectories (or not), as well as their adoption and application in and interference of Physical Education. This comparative and qualitative study used the review of documentaries, official documents and articles published in newspapers and websites to collect data referring to the last quarter of the 20 th century and the first of the 21 st century. In the analyzes, we rely on feminist, gender studies and public policies. We conclude that, although Argentina and Uruguay have anticipated Brazil in formulating legislation to tackle gender and sex discrimination, the three countries continue to face difficulties in the implementation and effectiveness of 
these policies in the field of education in both areas, specially nowadays, in view of the resistance of conservative sectors.

Keywords: Public policies in education, Gender and education, Comparative politics in South America.

\section{Introdução}

As conquistas de políticas públicas de gênero para a Educação na América Latina não podem ser analisadas sem considerar a conjuntura internacional favorável que embalou a temática de gênero e de diversidade sexual, principalmente após os anos 60 do século XX. A partir desse período, podemos observar uma crescente preocupação internacional a respeito dessa questão social, influenciada pelos movimentos feministas de todos os continentes (Ahmad, 1999; Madsen, 2008). O debate alcançou maior visibilidade política junto aos organismos internacionais Banco Mundial (BM); Organização das Nações Unidas para a Educação, a Ciência e a Cultura (UNESCO); Fundo das Nações Unidas para a Infância (UNICEF); Comissão Econômica para a América Latina e o Caribe (CEPAL) -, principalmente a partir da Conferência de Beijing, ocorrida em 1995.

Fruto das relações de forças sociais no campo dos direitos e também da influência de organismos internacionais e multilaterais, essa tendência se espraiou pela América Latina. As feministas engajadas nos movimentos sociais e nos partidos de esquerda passaram a travar lutas internas e externas para ter suas demandas garantidas como agenda e reivindicação. Simultaneamente, buscavam a implementação de políticas públicas como forma de superar os muitos problemas enfrentados pelas mulheres nos mais diversos campos: saúde, educação e segurança, dentre outros (Gohn, 2008).

Especificamente no campo da educação, entre final do século XX e início do século XXI, ${ }^{1}$ com a ascensão ao poder de governos mais populares - com uma preocupação mais forte em implementar políticas sociais, diversas políticas públicas relacionadas com gênero e educação foram conquistadas no eixo Brasil, Argentina e Uruguai. Produto de novos atores, imaginários, ordens simbólicas, movimentos sociais e políticos como os diferentes feminismos, os movimentos de dissidência sexual, e as produções queer, e de um quase -'receptivo' clima de época, neste período se produzem nos países analisados, agendas públicas que incorporam, não só na educação, políticas de gênero com uma intensidade e materialidade distinta a momentos anteriores, e com categorias (diversidade sexual, dissidências sexuais, ampliação de direitos etc.) que incluem novas formas de ler e interpretar criticamente as políticas de os corpos sexuados. Considerando isso, nosso objetivo, neste artigo, é analisar as políticas públicas de gênero para a educação no Brasil, na Argentina e no Uruguai e, por esse caminho, apresentar o percurso de criação dessas políticas nos três países, com vistas a delinear trajetórias comuns e diferentes, conforme suas conjunturas específicas, e suas aplicações e traduções ${ }^{2}$ no campo da Educação Física. 
Pensamos, como assinala Butler, que a diferença sexual nunca é sensivelmente uma função de diferenças materiais que não estejam de algum modo marcadas e formadas pelas práticas discursivas. De alguma maneira, a categoria de 'sexo' é, desde o começo normativa. Neste sentido o 'sexo' não funciona apenas como norma, mas é parte de uma prática reguladora que produz os corpos que governa, ou seja, cuja força reguladora se manifesta como uma espécie de poder produtivo, o poder de produzir - demarcar, circunscrever, diferenciar- os corpos que controla.

De tal modo que o 'sexo' é um ideal regulatório cuja materialização se impõe e se alcança (ou não) mediante certas práticas altamente reguladas. Em outras palavras o 'sexo' é uma construção ideal que se materializa obrigatoriamente através do tempo. Não é uma simples ou uma condição estática de um corpo, mas um processo mediante o qual as normas reguladoras materializam o 'sexo' e alcançam tal materialização em virtude da reiteração forçada dessas normas. Que esta reiteração seja necessária é um sinal de que a materialização nunca é completa, de que os corpos nunca acatam inteiramente as normas mediante as quais se impõem sua materialização (Butler, 1999). Essa naturalização produzida pelas reiterações, é, nas relações sociais de poder, transformada em desigualdades de direitos e de condições. A partir destes e outros conceitos, analizamos a forma como as políticas públicas de género vinculadas à Educação Física colocam em circulação certos princípios, categorias e normas que questionam a ideia de corpos, gêneros e sexualidades como algo natural e, ao mesmo tempo, impugnam um clássico axioma que atravessou a educação em geral e a disciplina en particular: 'a anatomía é destino'.

\section{Metodologia}

No presente estudo, comparativo, de cunho qualitativo, utilizamos a técnica de revisão documental de pesquisa. Tal procedimento (Baena, 2017) é um método que procura a análise e a interpretação de fontes secundárias, tais como arquivos, publicações bibliográficas impressas, digitais e audiovisuais de outros/as pesquisadores/as. Privilegiamos as publicações bibliográficas, mas também os documentos oficiais e as matérias publicadas em jornais e sites para a produção dos dados referentes s políticas públicas de gênero na educação no Brasil, na Argentina e no Uruguai, aplicadas especificamente ao campo da Educação Física entre o último quartel do século XX e o primeiro do século XXI. Na condução teórico-metodológica do estudo e nas análises dos dados, adotamos, como base, estudos feministas, de gênero e políticas públicas.

Durante o trabalho, destacamos/constatamos uma quase ausência de políticas públicas de gênero específicas para a área da educação física. Por esse motivo, realizaremos um debate abordando aspectos educativos de tais políticas, apresentando, quando houver, programas específicos à área, com o intuito de levantar pistas para o debate. Além disso, listaremos elementos sobre o leque possível de se abordar na escola, como, por 
exemplo, a educação do corpo, o movimento, a sexualidade, as práticas corporais, as identidades, as mulheres, etc.

Vale ressaltar que as políticas recentemente implantadas nos três países para proteger o direito de igualdade e de liberdade das mulheres e da comunidade de lésbicas, gays, bissexuais, travestis, transexuais ou transgêneros e queer (LGBTIQ), sofrem sérios riscos no quadro de ruptura da ordem manifestada pela crise econômica, política e social, que busca interromper um ciclo de expansão de direitos sociais. Desse modo, o direito, quando instalado no sentido de garantir ou avançar em direção às igualdades substantivas, acaba provocando tensões não somente na dimensão econômico-social, mas também na cultural. É nesse campo de tensões que pretendemos analisar as políticas públicas de gênero para a área da Educação e Educação Física nos três países mencionados. Para tal, inicialmente abordaremos as políticas de gênero para a educação em cada país e, por extensão, para a educação física, para, em seguida, apresentar uma análise comparativa que articule as políticas dos três países.

\section{Políticas Públicas de Gênero para a Educação e Educação Física no Brasil: Conquistas em Xeque?}

A redemocratização vivida pelo Brasil em meados da década de 1980 fez emergir uma nova constituição, em 1988. Segundo Deslandes (2015), ainda que o termo 'gênero' não conste desse documento, nele foram incorporados importantes princípios que garantiram espaço igualdade de gênero, o que possibilitou a emergência de leis subconstitucionais protetoras e antidiscriminatórias: proteção da mulher no mercado de trabalho, assistência gratuita s crianças em creches, licença-gestante, dentre outras.

Nos anos 1990, inicia-se no Brasil a construção da agenda de gênero na educação. ${ }^{3}$ Essa agenda foi construída a partir da importação de objetivos e metas relativamente à igualdade de gênero, fomentada principalmente por documentos internacionais e pelos compromissos firmados em favor da promoção dos direitos das mulheres. A ênfase na educação, como estratégia de diminuição da pobreza no mundo e de promoção do crescimento econômico, constituiu também a lógica dessa agenda internacional de gênero, com base no questionamento em relação às desigualdades de gênero (Madsen, 2008).

No campo da educação, pudemos ver a Lei de Diretrizes e Bases da Educação Nacional (LDBEN) de 1996, que, ainda de forma tímida, já propunha discutir princípios de igualdade, assim como manifestava apreço pela tolerância relativamente a gênero. Além da LDBEN, segundo Vianna e Unbehaum (2006), um marco importante da década de 1990, nos avanços da perspectiva de gênero nas políticas para a educação foi a publicação, em 1997, dos Parâmetros Curriculares Nacionais (PCNs) para o ensino fundamental.

Os PCNs não configuravam uma política de execução obrigatória; ao contrário, eram uma referência na elaboração ou revisão curricular dos estados e municípios, já que deveriam respeitar a realidade social local. 
Apesar de terem sofrido críticas de estudiosas da temática gênero (Auad, 1999; Altmann, 2001; Vianna, Unbehaum, 2006), especialmente quanto ao seu caráter centralizador, tendo em vista as características políticas e geográficas diversas do território brasileiro, foram reconhecidos por trazerem como novidade os cadernos dos temas transversais. Dentre tais cadernos, a destacar o relativo à 'Orientação Sexual', não só por ter dado "[...] maior ênfase ao gênero nos conteúdos escolares, oficializando o tema (correlação gênero e sexualidade) nas escolas, prenunciando uma série de desenvolvimentos pedagógicos em relação ao tema" (Deslandes, 2015, p. 36), mas também por se aplicar ao campo da educação física. Especificamente para esta área, traziam nas orientações didáticas o eixo da "diferença entre meninos e meninas", apontando seu caráter social e cultural, com destaque para a importância de se propiciar experiências de respeito às diferenças e de intercâmbio entre meninos e meninas, estimulando as aulas mistas, de forma a criar possibilidades co-educativas 4 (Ministério da Educação - MEC/Secretaria de Educação Fundamental - SEF, 1998). A adoção de aula ministradas conjuntamente para meninos e meninas foi um grande avanço, assim como foi o abandono da atuação dos/as professores/as conforme o sexo dos/as alunos/as.

Nessa esteira, em 2001, Plano Nacional de Educação (PNE) abordava a necessidade de se tratar a respeito da produção de estereótipos de gênero nas escolas de educação básica, de forma que a temática fosse trabalhada transversalmente em todas as disciplinas, inclusive na Educação Física; e também na formação docente e subsidiasse informações relevantes para a formulação de políticas de gênero no ensino superior.

Madsen (2008) chama a atenção para a existência de dois períodos no processo de construção da agenda de gênero no Brasil. No primeiro momento, de 1996 a 2003, no governo de Fernando Henrique Cardoso, período em que a agenda brasileira esteve fortemente atrelada à agenda internacional de educação. No segundo, de 2003 a 2007, ${ }^{5}$ no governo de Luiz Inácio Lula da Silva, o Estado se organizava com uma estrutura institucional que tratava das questóes de gênero, criando a Secretaria de Políticas para Mulheres (SPM). ${ }^{6}$ Essa secretaria, criada em 2003, assumiu o papel não só de impulsionadora, mas também de articuladora dessa nova institucionalização. A formação em gênero passou a ser encarada como uma política pública a ser desenvolvida pela SPM. Não menos importante foi a criação das 'conferências nacionais', tanto de políticas para mulheres como de educação, fruto da política de concertação ${ }^{7}$ adotada pelo governo de Luiz Inácio Lula da Silva (2003-2007).

Esses novos mecanismos constituíram também significativos instrumentos de pressão. Por essa configuração de diálogo e pressão é que se organizavam novas institucionalidades, dentre elas a Secretaria de Educação Continuada, Alfabetização, Diversidade e Inclusão (SECADI), com a função de articular ações de inclusão social e valorização da diversidade (Vianna; Unbehaum, 2016).

Foi nesse processo de ampliação de direitos e de espaços institucionais, também como resultante do Plano Nacional de Políticas para as Mulheres (PNPM) que, em 2006, foi criado o Curso de Gênero e Diversidade 
na Escola (GDE) ${ }^{8}$ no âmbito do governo federal. O curso se tornou uma política pública que articulava as temáticas gênero, relações étnicoraciais e orientação sexual ${ }^{9}$ (Auad, 2008; Rohden, Carrara, 2008). Dornelles e Wenetz (2019, p.14) consideram que o GDE “[...] aciona um repertorio intersecional potente para a formação de professores/ as, articulando gênero, sexualidade, raça/etnia [...]”. Problematizam, contudo, os modos de operar com a diversidade, identificando uma naturalização dos conceitos de gênero e sexualidade nas políticas públicas, invisibilizando os corpos.

Além da política do GDE, voltada a professoras e a movimentos sociais, foi criado o curso Gestão de Políticas Públicas em Gênero e Raça (GPPGeR), direcionado aos/às gestores/as da educação. O curso seguia formato semelhante ao dos cursos ofertados pela Secadi na modalidade $\mathrm{EaD}$, como o GDE, ou seja, composto por professores/as formadores/as e professores/as tutores/as.

É inegável o incremento de políticas públicas de gênero para a educação nos governos de Luiz Ignácio Lula da Silva (2003-2011) e de Dilma Vana Rousseff (2011-2016). No entanto, a perspectiva de esses governos privilegiarem a implementação de políticas públicas de gênero para a educação, pelo viés da educação continuada e na modalidade educação a distância, foi problematizada: de um lado, apontavam-se os limites que essa modalidade de formação apresentava e, de outro, as possibilidades de alcance dessa política em levar formação a territórios e lugares os mais distantes em um país de dimensões continentais.

Ainda que não desconsiderando as críticas, é possível afirmar que as políticas, ${ }^{10}$ de caráter indutivo, implementadas pelo governo federal nesse interstício temporal, especialmente a política pública relativa a "Gênero e Diversidade na Escola", provocaram a agenda de gênero na educação e na Educação Física dos estados e municípios. Em que pese toda a complexidade que envolve desenvolver política em um país federativo como o brasileiro, diversos cursos no campo dos direitos humanos ${ }^{11} \mathrm{e}$ outros no campo da discussão de gênero foram realizados a partir da adesão e parceria dos estados e municípios às políticas emergidas do governo federal. A realização dos cursos também foi importante como um estímulo para produções bibliográficas locais, já que, na alocação de recursos para a realização dessas políticas, havia uma rubrica destinada a publicações.

Ainda nesse contexto, vimos serem aprovadas outras legislações que dizem respeito à garantia de permanência das pessoas LGBTIQ nas escolas, como a Resolução CNE/CP n 1 , de 19 de janeiro de 2018, que define o uso do nome social de travestis e transexuais nos registros escolares. Mais recentemente, em março de 2018, o Supremo Tribunal Federal decidiu favoravelmente à possibilidade de que transgêneros alterem o sexo e o nome presentes no registro civil em cartório, sem precisar obter autorização judicial. Essa decisão impacta diretamente a vida estudantil dessa população, em especial no que tange as aulas de Educação Física que tem o corpo e o movimento como objeto de ensinoaprendizado. Outra decisão importante foi a aprovação de uma resolução, 
em maio de 2013, pelo Conselho Nacional de Justiça (CNJ), que passou a obrigar os cartórios de todo o país a celebrar o casamento civil e a converter a união homoafetiva estável em casamento. Essas políticas, ainda que sujeitas as traduções nos cotidianos escolares, colocam em circulação questionamentos às naturalizações produzidas sobre os corpos, os gêneros e as sexualidades e, ao mesmo tempo, potencializam sobremaneira o olhar da unidade curricular da educação física sobre o corpo. Um corpo com outros direitos é um corpo que pode vir a se 'mover' e se mobilizar diferente na escola. Esse corpo passa a ter um nome que se alinha ao de sua identidade.

Essas traduções que nem sempre acompanham os avanços trazidos pelas legislações se expressam em diversos artigos e publicações no campo da Educação Física que denunciam a existência de preconceitos e estereótipos em torno das feminilidades e masculinidades que dificultam meninas a acessarem as práticas de futebol nas aulas de Educação Física escolar (Darido, Souza, 2002; Furlan, Santos, 2008; Macagnan, Betti, 2014) e os meninos de praticarem as aulas de Educação Física com o conteúdo dança (Brasileiro, 2009; Kleinubing, Saraiva, Francischi, 2013; Nascimento, Castro, 2016).

Os avanços obtidos com o desenvolvimento das políticas implementadas nos governos populares entre os anos de 2003 e 2016, ainda que tímidos e de difícil implementação, ${ }^{12}$ indicavam a existência de um movimento pedagógico de gênero nas escolas (Silva; Ferreira, 2019) em relação às políticas de gênero e em torno do reconhecimento das diferenças de gênero e sexualidade. No entanto, principalmente a partir de 2014, esse movimento vêm correndo sérios riscos de retrocessos, tendo em vista um cenário político bastante complexo no Brasil: o golpe (parlamentar e jurídico) com o afastamento de Dilma Vana Rousseff da Presidência; a elevação de seu vice, Michel Temer (2016-2018), à Presidência da República e, em 2018, a eleição de um presidente de extrema direita, Jair Bolsonaro (2019).

Com isso, a partir de 2019, vemos, dia após dia, numa métrica frenética, uma série de conquistas sociais serem questionadas, ou mesmo extintas, como a SPM e a SECADI, ou mantidas mas esvaziadas, como a Secretaria de Políticas de Promoção da Igualdade Racial (SEPPIR) e as secretarias e as coordenações constituídas para tratar dos temas referentes aos direitos humanos no MEC. ${ }^{13}$ Toda essa virada política está de mãos dadas com perspectivas apontadas pelo projeto "Escola sem Partido" ${ }^{14}$ e pelo projeto "Ideologia de Gênero", ${ }^{15}$ implicando sério retrocesso na construção e consolidação das políticas de gênero como políticas públicas. Nesse processo de tensões políticas, inferimos sobre a possibilidade de que essas investidas conservadoras estejam relacionadas exatamente com o crescimento e o aprofundamento de políticas públicas de gênero nos diversos campos, inclusive na Educação e Educação Física, nos últimos anos no Brasil. Neste momento, a despeito dessas investidas conservadoras e de certo receio instalado, vemos que o debate sobre gênero continua a ser realizado pelas escolas e no campo específico da Educação 
Física (Freitas, 2019). Vejamos, a seguir, como tem acontecido o debate no país vizinho, a Argentina.

\section{Políticas Públicas de Educação com Articulações de Gênero e Sexualidade na Argentina}

$\mathrm{Na}$ Argentina, nas últimas três ou quatro décadas, produziram-se várias mudanças semânticas e materiais em relação à sexualidade e aos gêneros tradicionalmente produzidos/transmitidos pelo discurso pedagógico patriarcal moderno. As mudanças mais abruptas na área pedagógica e nas políticas educativas, porém, pelo menos no plano retórico, se produziram nas duas últimas décadas. As discussões geradas condensaram, no contexto das preocupações transnacionais, os ecos críticos da segunda onda do feminismo dos anos '60 e '70 da nova sociologia crítica da educação, com a incorporação da briologia sociológica (gênero, classe e etnia), do giro linguístico e, nos anos 80 , da teoria queer, os estudos pós-críticos em educação, os estudos sobre masculinidades, as reivindicações e lutas da militância social e as reclamações do movimento LGBTQ+. Ditos movimentos epistemológicos comoveram boa parte das grelhas interpretativas com as quais se 'liam' e analisavam os corpos.

Em particular, nos últimos 15 anos (excetuando a gestão de Cambiamos ${ }^{16}$ ), além de certas resistências de atores vinculados a corporações religiosas e atores vinculados ideologicamente à direita, as legislações e as políticas sobre sexualidades, gêneros e identidades 'dissidentes' se materializaram, ampliando direitos e gerando justiça social a coletivos historicamente minorizados, subalternizados e violentados por distintas instâncias sociais, entre eles o próprio Estado. Neste receptivo, embora tenso, clima da época se produziu um corpus legislativo amplo, heterogêneo e diverso, que contemplou uma importante quantidade de leis com suas implicações na vida cotidiana dos/as cidadãos/ãs. ${ }^{17}$ Ditas leis contemplaram a saúde reprodutiva, a luta contra os cuidados com as pessoas, a prevenção e a erradicação da violência contra as mulheres; o direito à identidade de gênero e ao matrimonio igualitário, etc.

A partir da sanção da lei de Educação Sexual Integral (ESI) e da aprovação dos Lineamentos Curriculares de Educação Sexual Integral, os/as docentes da Argentina tiveram a obrigação, a responsabilidade e, ao mesmo tempo, a oportunidade de transmitir, problematizar e ensinar desde uma perspectiva transversal e integral educação sexual as crianças e jovens. O Ministério de Educação conceituou a ESI como o espaço sistemático de ensino/aprendizagem e promoveu, não sem conflitos e dificuldades, saberes e habilidades para a tomada de decisões conscientes e críticas em relação ao cuidado do próprio corpo, às relações interpessoais, ao exercício da sexualidade e dos direitos de crianças e jovens. Compreendeu conteúdos de distintas áreas e disciplinas, e considerou acontecimentos da vida cotidiana das salas de aula e da escola, assim como suas formas de organização.

A ESI converteu-se em um direito para meninas e meninos de todas as escolas argentinas, privadas ou estatais, confessionais ou laicas, de 
nível inicial, fundamental, médio e superior. ${ }^{18}$ Os objetivos da ESI sustentaram o paradigma dos direitos e a integralidade como perspectiva teórica. Isso implicou problematizar os corpos, as sexualidades e os desejos ancorados numa perspectiva histórico-social que questionava as visões naturalizantes e reducionistas, ou seja, biologicistas, moralistas ou estritamente biomédicas.

A Educação Sexual Integral (ESI), por ser transversal, implicou problematizar e transmitir a educação sexual além de uma área disciplinar ou matéria específica (Ciências Naturais, Biologia ou Educação para a Saúde), interpelando os conteúdos de todos os espaços curriculares, incluídos os da Educação Física. Esta disciplina educativa foi incorporada nos materiais elaborados pelo Ministério de Educação, problematizando sua história e seu presente. Por exemplo, parte do material elaborado em 2012, no contexto da ESI, para a Educação Física no ensino médio, objetou questionar as representações hegemônicas sobre feminidade e masculinidade. Esse material questiona as sociedades ocidentais quanto às suas representações hegemônicas, que "[...] estabelecem claramente um mundo do feminino e um mundo do masculino e isso impacta fortemente nas ideias do corpo de mulheres e corpo de homens [...]"(Argentina. Ministerio de Educación de la Nación, 2012a, p. 44). ${ }^{19}$ Esse modelo tradicional de ensinar no campo da Educação Física nas escolas acaba por fortalecer essa distinção.

O material ofereceu propostas de ensino com o fim de identificar "[...] os modos em que se reproduzem, ou se reflexiona criticamente, sobre os modelos e estereótipos de gênero presentes na cotidianidade escolar, no vínculo entre docentes e alunos, nas relações pais/escola", ${ }^{20}$ (Argentina. Ministerio de Educación de la Nación 2012b, p. 54) a partir de diferentes perguntas sobre a vida cotidiana nas classes de educação física. A luta contra os estereótipos de gênero, a promoção de igualdade de oportunidades para o exercício de esportes de homens e mulheres, o deslanche da comunicação corporal entre homens e mulheres que enfatiza o respeito, a responsabilidade, a solidariedade e o cuidado por si mesmo e pelo outro, a reflexão e a análise crítica em torno da valoração de padrões hegemônicos de beleza e da relação com o consumo foram alguns dos objetivos procurados.

Muitas dessas finalidades se condensaram e se traduziram nas normativas referidas à educação física de vários estados argentinos, a partir de distintos questionamentos. Por um lado, as formas de agrupamento das classes de educação física, historicamente separadas por sexo; por outro, o exercício da docência dessa disciplina, que até pouco tempo atrás era a única que exigia professores homens para ministrar aulas aos meninos e professoras mulheres para as aulas com as meninas. As aulas mistas se transformaram no grande significante a conquistar a partir da perspectiva crítica de gênero esboçada na ESI.

Ainda que estas questões tenham sido significativas e historicamente necessárias, as normativas vinculadas à educação física em diferentes estados mantiveram um evidente ranço binário (homens e mulheres), e um silêncio sobre as 'dissidências' sexuais, omissões sobre as economias de 
desejo não heteronormativas e uma ausência epistemológica e pedagógica sobre coletivos sexuais historicamente excluídos, como o universo trans (Scharagrodsky, 2019). Isso não somente constituiu base para a educação física, mas também para a ESI (Perez Riedel; Scharagrodsky, 2020). Como afirma a filósofa e ativista trans Alba Rueda, além da importância políticopedagógica da ESI, as suas referências ampliam o leque dos direitos e da diversidade sexual. No entanto, sobre o material ESI, a lei e seu Programa, publicado em (2018) Alba Rueda destaca não contam com informação precisa nem abordam as diferenças de relações de poder que oprimem as pessoas travestis e trans, não propõem ferramentas pedagógicas para abordar a violência em nossos percursos de vida, e especialmente nas instituições educativas.

Se as escolas foram identificadas como espaços hostis por grande parte do coletivo trans, ${ }^{21}$ um dos grupos ocupacionais mencionado como um dos mais violentos, adversos e insensíveis tem sido - e continua a ser - é o dos professores de educação física (Scharagrodsky, 2019). Frente a este panorama de vulnerabilidade e abjeção (Butler, 2019), os desafios das políticas públicas na educação e, muito especialmente, no da educação física, devem convidar essa comunidade a questionar e interpelar a heteroesportividade obrigatória. Essa heteroesportividade, como regime cinético, moral e emocional sobre o corpo continua operando como instrumento para circunscrever e conformar determinada forma de conformar o movimento, as posições corporais, as expressões, as emoções físicas, aos universos gestuais e aos cânones de beleza atados binariamente ao desejo e aos prazeres. Ao fazer isso, exclui outras alternativas possíveis de pensar, experimentar, sentir e viver os corpos em movimento. Incluir estas e outras problematizações faz parte dos desafios a serem materializados nas políticas e legislações educativas e da educação física, com a finalidade de torcer, forçar, quebrar e revisar os limites das epistemes dominantes (Britzman, 2016) e poder imaginar e projetar aulas de educação física mais justas, empáticas, democráticas e respeitosas.

A realização da análise dessas leis e documentos permite visualizar os avanços e retrocessos dos modos e ação das políticas públicas e a articulação da área da educação física com a temática gênero e sexualidade; articulação não linear, nem homogênea, que permite visualizar avanços e retrocessos, mas que ainda legitima a heterossexualidade. Veremos, a seguir, conferir como isso acontece em nosso vizinho país, o Uruguai.

\section{A Heteronormatividade no Sistema Educativo Uruguaio e a Suposta "Ideologia de Gênero"}

O Uruguai se tem historicamente destacado na região latino-americana por ter leis de vanguarda. ${ }^{22}$ Contudo, teve que lidar sempre com o conservadorismo, com a 'velha' disputa entre leis avançadas e discursos conservadores, que parecem conviver até hoje no país, o que Real de Azúa (1964) chamou de impulso e seu freio. Isto se evidencia também em relação às políticas públicas de educação, de gênero e diversidade sexual. Neste tópico, identificaremos, nas políticas públicas de educação, 
de gênero e de diversidade sexual, as resistências às mudanças que as leis habilitam em relação aos direitos das pessoas.

No sistema educativo uruguaio, o Conselho Diretivo Central (CODICEN) é um órgão central da Administração Nacional de Educação Pública, autônomo e com representação jurídica. Foi criado pela Lei $\mathrm{n}^{\circ} 15.739$, em 28 de março de 1985, poucos dias depois da retomada da democracia no Uruguai, após uma ditadura cívico-militar que durou quase 12 anos.

Em relação às políticas públicas de educação e educação sexual, apesar de o Codicen discutir a temática desde o ano de $2005,{ }^{23}$ somente em 2012 é que a associação civil Espacio Salud, a pedido de Inmujeres-Mides ${ }^{24}$ CEIP $^{25}$, editou o Guia Didático: A Educação Física sob um Enfoque de Gênero, e em 2014 o coletivo Ovejas Negras ${ }^{26}$ elaborou o Guia Didático de Educação e Diversidade Sexual editada pela Inmujeres-Mides. No ano de 2017 o Fundo de População das Nações Unidas (UNFPA), a Ong Gurises Unidos, ${ }^{27}$ e o Conselho de Educação Inicial e Primária (CEIP) editaram o Guia Didático de Educação Sexual.

Tais Guias Didáticos de Educação e Diversidade Sexual (INMUJERES-MIDES, 2014) e o de Educação Sexual (GURISES UNIDOS, 2017) sofreram resistência por parte da sociedade uruguaia conservadora que, mediante manifestações em via pública e midiaticamente, se pronunciou contrária à sua publicação. Assim foi que, no caso do Guia de Educação e Diversidade Sexual, foi publicado uma única vez, para depois deixar de ser publicado. Após as polêmicas, o Codicen resolveu "[...] elaborar um guia de educação e diversidade sexual para seu uso nos centros educativos da Anep e aos distintos níveis educativos e idades dos estudantes" (EL OBSERVADOR, 2015, s.p.).

Sempol (2013) afirma que o Uruguai tem vivido, nos anos 1990, um processo de politização da diversidade sexual, associado a um progressivo fortalecimento do movimento de diversidade sexual e de seu poder de colocar seus temas na agenda. Assim, em poucos anos, avançou-se na implantação de leis, por parte do Poder Legislativo, o que foi uma grande conquista em relação aos direitos das pessoas LGBTIQ. ${ }^{28}$

Segundo Schenck (2014), excluíram-se diferentes tipos de sexualidade dos currículos, denominados currículos ocultos, manifestando um tipo de violência física e outro tipo de violência verbal, ou de atitudes segregadoras da diversidade.

Podem-se observar dificuldades no sistema educativo, dentre as quais a de pessoas que nele trabalham sentirem que não existe uma política clara em relação à diversidade sexual, apesar dos avanços em nível legislativo e na elaboração de guias que tratam dos temas de educação, gênero e diversidade sexual (Schenk, 2014). Da mesma forma existem outras dificuldades, denunciadas pelos (as/es) estudantes. A pesquisa nacional de ambiente escolar no Uruguai 2016, elaborada no ano 2016 pelo coletivo Ovejas Negras (em colaboração com Gay, Lesbian \& Straight Education Network (Glsen, USA) e a Fundação Todo Mejora (Chile), coloca em evidência que as aulas de educação física são o espaço educativo em que 
as pessoas pertencentes à população LGBTIQ sentem-se mais inseguras no centro de estudos (Ovejas Negras, 2016). Já o censo de pessoas trans elaborado pelo Mides em 2016 evidencia que 61\% das pessoas não têm o ciclo de educação básico completo (12\% não finalizaram a escola, $25 \%$ têm primária incompleta, e $24 \%$ ensino médio incompleto), sendo que $47 \%$ das pessoas censadas declararam ter sido discriminadas na escola e 37\% no ensino médio (MIDES-ANEP, 2019).

Em relação ao Guia de Educação Sexual, ${ }^{29}$ surgiram, de uma parte da sociedade uruguaia, diversas manifestações contra ele, que se materializaram em manifestações públicas de grupos conservadores e em cartas de repúdio nos meios de comunicação de opiniões, de parte da Igreja católica, assim como de grupos evangélicos conservadores.

Ditos discursos conservadores que se pronunciam contra uma suposta "ideologia de gênero" têm sido recorrentes nos últimos anos e se apresentam como uma resistência e uma suposta vulnerabilidade dos grupos conservadores ao avanço em matéria de direitos humanos e diversidade sexual das pessoas. Essas manifestações dos grupos conservadores, não condizem com as pesquisas realizadas em diversos âmbitos (Schenck, 2014). Pelo contrário, tais grupos colocam-se como vítimas de discriminação, quando, na realidade, o que prevalece no sistema educativo é a heteronormatividade (Schenk, 2014).

Como afirmado, a suposta "ideologia de gênero" é parte de um discurso conservador que se vem desenvolvendo nos últimos anos e, com base nesse discurso, surgem ataques a tudo o que tenha a ver com a temática de gênero e diversidade sexual.

O Uruguai é um dos países da América Latina em que a Igreja católica não faz parte da Constituição nacional; mesmo assim, a impressão que se tem é que sua influência não é menor que em outros países da região, o que se pode evidenciar nas palavras do cardeal Sturla, que dá a entender, ao falar de educação sexual na educação, que o Uruguai vive na atualidade em um estado totalitário (MONTEVIDEO PORTAL, 2017).

O Guia de Educação Sexual propõe uma reflexão sobre o gênero e a sexualidade, questionando certos estereótipos heteronormativos e crenças construídas e constituídas pela linguagem, como bem manifestou Butler (1999). Esse guia é claro em sua proposta didática relativamente à abordagem da educação sexual em educação inicial e básica: pretende ser um marco de referência em questão de transversalização da educação sexual na escola. Ademais, coloca-se como uma ferramenta que oferece aportes fundamentais de reflexão ao trabalho docente quanto aos conceitos de sexualidade, gênero e diversidade sexual.

A América Latina foi considerada recentemente pela ONU como uma das regiões mais violentas do mundo e considerada a mais violenta em relação às mulheres (EL ESPECTADOR, 2017). Neste sentido, as pessoas, os grupos de pesquisa e da sociedade civil que trabalham com a temática 'gênero e diversidade sexual' acreditam que a educação sexual seja um dos tantos pilares a se trabalhar para erradicar a violência de gênero.

Se evidencia nas pesquisas que as escolas e centros educativos de educação média no Uruguai são hostis às pessoas pertencentes ao coletivo 
LGBTIQ, e especificamente as aulas de educação física são consideradas como as mais inseguras. Porém, as políticas educativas e especificamente as políticas de educação física, deveriam colocar seu foco em reverter a violência e discriminação que se observa no ambiente educativo uruguaio. Atendendo as recomendações que colocam nesse sentido o coletivo Ovejas Negras (2016, p.34), se deveria promover a formação em diversidade sexual de todo o pessoal que trabalha na educação e em especial dos(as/es) professores; gerar formas concretas de resolução de situações de violência e discriminação que ocorrem nas escolas por causa da orientação sexual e identidade de gênero; incluir as famílias e pessoas referentes adultas na difusão das normativas e convivência respeitosa da diversidade sexual; revisar as normativas vigentes nos centros educativos.

Em relação às populações vulneráveis e à violência de que é alvo a população LGBTIQ, Butler escreve "[...] primeiro você resiste, e então você é confrontado com a sua vulnerabilidade em relação ao poder da polícia ou àqueles que aparecem para se opor à sua posição política" (2016, p. 12). Para a autora, a vulnerabilidade não é necessariamente superada com a resistência, mas serve como potencial efetivo de mobilização.

\section{Entre Tensões e Projeções: articulando o comum e o particular, à guisa de Conclusão}

Em relação à construção de políticas públicas de gênero para a Educação e Educação Física, é possível perceber, nas políticas públicas dos países em análise, em especial a partir da década de 1990, a interferência de organismos internacionais na indução de legislações que admitem e estabelecem garantias e direitos no que tange às temáticas gênero e diversidade sexual. No entanto, é possível indicar que o tempo de elaboração dessas legislações foi condicionado pela correlação de forças e tensões políticas de cada país. $O$ fato é que as agendas internacionais e as ações reivindicatórias dos movimentos de mulheres, feministas e comunidades LGBTIQ dos três países influenciaram a construção de uma Agenda de Gênero e de Diversidade Sexual para a Educação no Brasil, na Argentina e no Uruguai.

Neste sentido, podemos inferir, por um lado, que obtivemos significativos avanços quanto à publicação de legislações que criam direitos e fomentam o debate de gênero e diversidade sexual nos currículos, inclusive com uma perspectiva de transversalidade institucional e curricular; por outro, vemos que, também nos três países, há dificuldades de efetivação dessas legislações, por esbarrarem em uma cultura ainda bastante patriarcal de base. No caso do Brasil, essas dificuldades de implementação de políticas públicas de gênero aumentam devido à pouca articulação entre os entes federativos e as dimensões continentais do país. Vale ressaltar que no Uruguai, verificamse conquistas através de leis, por parte do poder legislativo, em relação aos direitos das pessoas LGBTIQ, mas, nota-se ainda a ausência de uma política educativa que seja transversal na educação, inclusive na educação física, a qual se corrobora como o espaço mais inseguro dentro do centro 
educativo, de modo que muitos estudantes LGBTIQ decidem não assistir a tais aulas como uma estratégia de sobrevivência (Ovejas Negras, 2016). No caso da Argentina, tem se realizado mais material didático e formação dos professores, mas isso ainda não significa o desenvolvimento integral desses conteúdos no contexto escolar, em função de resistências culturais ou religiosas ainda presentes.

Ditos entraves atravessam a área da educação física na medida em que afetam as sexualidades e os corpos de seus alunos e alunas. Reconhecemos um avanço no currículo dos três países em debater o tema - gênero e diversidade sexual -, embora precisemos reforçar a formação dos/as professores/as para nos afastar de uma visão meramente biológica e contribuir para uma efetiva concretização de tais políticas, em especial as atinentes à comunidade LGBTIQ. A sexualidade, às vezes incluída, mas diluída nesse processo, precisará de nossos investimentos em favor de uma política de enfrentamento que corresponda a um processo educacional para o exercício da cidadania. Isso, especialmente na atualidade, quando vemos projetos conservadores, como os denominados "Escola sem Partido" e "Ideologia de Gênero", que avançam sobre os três países estudados. Neles identificamos uma maior resistência no âmbito legislativo/parlamentar do que no nível escolar, questionando a existência de políticas de gênero e de diversidade sexual para a educação e, consequentemente, para a educação física. Quanto ao quotidiano escolar, as resistências no plano legislativo/parlamentar, estimulam resistências no âmbito da produção de conhecimento.

\section{Referências}

Ahmad, A. (1999). Cultura, nacionalismo e o papel dos intelectuais. In: Wood, E. M.; Foster, J. B. Em defesa da história: marxismo e pós-modernismo. Rio de Janeiro: Jorge Zahar Editora. 59- 73.

Altmann, H. (2001). Orientação sexual nos Parâmetros Curriculares Nacionais. Revista Estudos Feministas, 9(2), 575-585.

Argentina. Ministerio de Educación de la Nación. (2012). Serie Cuadernos da ESI. Educación sexual integral para la educación secundaria II: contenidosy propuestas para el aula. Recuperado de: http://bnm.me.gov.ar/giga 1/doc umentos/EL005009.pdf. Acesso em: 20 mar. 2019

Argentina. Ministerio Público de la Defensa de la Ciudad Autónoma de Buenos Aires. (2017). La revolución de las mariposas. $A$ diez años de la Gesta del Nombre Propio. Recuperado de: https://www.mpdefensa.gob.ar/publicaciones/la-revolucion-las-mari posas-a-diez-anos-la-gesta-del-nombre-propio. Acesso em: 1 mar. 2018.

Argentina. Secretaria de Derechos Humanos de la Provincia de Buenos Aires. (2019). Primer relevamiento sobre condiciones de vida de la población trans/ travesti de la provincia de Buenos Aires.

Auad, D. (1999). Os parâmetros curriculares nacionais e os temas transversais. In: Faria, N.; Auad, D.; Carvalho, M.; Nobre, M. Caderno Educação e Gênero. São Paulo. Sempre Viva Organização Feminista/SOF.

Auad, D. (2008). O Curso Gênero e Diversidade na Escola como uma Proposta de Política Igualitária. In: Rohden, F., Araújo, L.; Barreto, A. (Orgs.). Os 
desafios da transversalidade em uma experiência de formação on line: Curso Gênero e Diversidade na Escola. Rio de Janeiro: Cepesc.

Baena, P.G.M.E. (2017). Metodología de la investigación (3ra ed.). Ciudad de México: Grupo Editorial Patria.

Berkins, L. (Org.). (2007). Cumbia, copeteo y lágrimas: Informe nacional sobre la situación de las travestis, transexuales y transgéneros. Buenos Aires: A.L.I.T.T. Asociación de lucha por la identidad Travesti-Transexual.

Berkins, L.; Férnandez, J. (2005). La gesta del nombre propio. Informe sobre la situación de la comunidad travesti en la Argentina. Bs. As., Ediciones Madres de Plaza de Mayo.

Brasil/Ministerio de Educação (MEC)/Secretaria de Educação Continuada, Alfabetização, Diversidade e Inclusão (SECADI). (2015). Recuperado de: http://portal.mec.gov.br/index.php?Itemid=541\&id=290\&option= com_content\&view=article. Acesso em: 15 mai.

Brasileiro, L. T. (2009). Dança - educação física: (in) tensas relaçôes. Tese de doutorado, Unicamp, Campinas, SP, Brasil.

Britzman, D. (2016). “¿Hay una pedagogía queer? O, no leas tan recto”. Revista de Educación, 7, (9), 13-34.

Butler, J. (2019). Vulnerabilidad del cuerpo y la política de coaliciones. In: Cuerpos aliados y lucha politica. Hacia una teoría performativa de la asamblea. Buenos Aires: Paidós. 125-155.

Butler, J. (1999). El género en disputa. Barcelona: Paidós.

Butler, J. (2016). Rethinking vulnerability and resistance. In: Butler, J., Gambetti, Z.; Sabsay, L. Vulnerability in resistance. Durham: Duke university press. 12-27.

Darido, S. C.; Souza, O. P. (2009). A prática do futebol feminino no Ensino Fundamental. Revista Motriz, Rio Claro, 8 (1), 1-8.

Deslandes, K. (2015) Formação de professores e direitos humanos: construindo escolas promotoras da igualdade. Belo Horizonte, Autêntica Editora; Ouro Preto-MG, Ufop.

Dornelles, P.G.; Wenetz, I. (2019). Uma análise generificada sobre o Projeto Gênero e diversidade na Escola. Cadernos de pesquisa. São Paulo, v. 49, n. 173, p. 226-243. Jul./set.

El Espectador. (2017). América latina es la región más violenta del mundo contra las mujeres. Recuperado de: https://www.elespectador.com/noticias/el-mundo/america-latina-es -la-region-mas-violenta-del-mundo-contra-las-mujeres-articulo-72454 8>. Acesso em: 22 nov.2017.

El Observador. (2015). La guia educación y diversidad sexual morirá en un cajón. Recuperado de: https://www.elobservador.com.uy/la-guia-educacion-y-d iversidad-sexual-morira-un-cajon-n299870 >. Acesso em: 7 mar.2015.

Freitas, S. P. (2019). Em tempos de discursos de ideologia de gênero na educação: o que dizem pensar e como dizem agir as professoras de educação física do município de vila velha/es. 2019. 71f. Trabalho de conclusão de curso (graduação). Universidade Federal do Espírito Santo, Vitória.

Furlan, C.C.; Santos, P. L dos. (2008). Futebol Feminino e as Barreiras do Sexismo nas Escolas: reflexões acerca da invisibilidade. Motrivivência, Ano XX, n. 30, 28-43. 
Gohn, M. G. M. (2008). Teoria dos movimentos sociais: paradigmas clássicos e contemporâneos. 7. ed. São Paulo: Loyola.

Guzmán, M. A. B. Aborto Legal Ya Recuperado de: http://clam.org.br/destaqu e/conteudo.asp?cod=12748>. Acesso em: 20 ago. 2018.

Gurises Unidos. (2017). Propuesta didáctica para el abordaje de la educación sexual en educación inicial y primaria. Recuperado de: https://www.gurisesunidos.org.uy/wp-content/uploads/2017/07/G u\%C3\%ADa-Educación-Sexual.pdf. Accesso em: 22 nov. 2017.

Instituto Nacional de las Mujeres-Ministerio de Desarrollo Social (INMUJERES-MIDES). (2012). Guia didáctica: la educación física desde un enfoque de género. Recuperado de: http://guiaderecursos.mides.gub. uy/innovaportal/file/21303/1/edfisica_genero.pdf $>$. Acesso em: 5 out. 2020.

Instituto Nacional de las Mujeres-Ministerio de Desarrollo Social (INMUJERES-MIDES). (2014). Guia didáctica de educación y diversidad sexual. Recuperado de: http://www.inmujeres.gub.uy/innovaportal/file/ 40883/1/guia-didactica-educacion-y-diversidad-sexual-uy-version-final. pdf >. Acesso em: 12 mar. 2018.

Kleinubing, N. D.; Saraiva, M. C.; Francischi, V. G. (2013). A dança no ensino médio: reflexões sobre estereótipos de gênero e movimento. Rev. Educ. Fis/ UEM, 24 (1), 71-82.

Macagnan, Leandro Del Giudice, \& Betti, Mauro. (2014). Futebol: representações e práticas de escolares do ensino fundamental. Revista Brasileira de Educação Física e Esporte, 28(2), 315-327. https://doi.org/1 $0.1590 / 1807-55092014000200315$

Madsen, N. (2008). A construção da agenda de gênero no sistema educacional brasileiro (1996-2007). Dissertação (Mestrado) - Departamento de Sociologia, Universidade de Brasília - Brasília.

Mainardes, J.; Marcondes, M. I. (2009) Entrevista com Stephen J. Ball: um diálogo sobre justiça social, pesquisa e política educacional. Revista Educação e Sociedade, Campinas, vol. 30, n. 106, p. 303-318, jan./abr.

Ministerio de Desarrollo Social (2014) Poli\#ticas pu\#blicas, regulaciones discriminatorias y diversidad sexual. Informe final.Schenck, M. Con la violencia heteronormativa en el armario: el desafi\#o de visibilizar formas naturalizadas de discriminacio\#n en el a\#mbito educativo en silencios y otras violencias. p. 89-119. Montevideo: Ministerio de Desarrollo Social. Recuperado de: http://ovejasnegras.org/es/wpcontent/uploads/2016/07 /Libro_Diversidad_sexual_V_1.pdf>. Acesso: em 25 de julho de 2018.

Ministerio de Desarrollo Social. (2014) Diversidad sexual en Uruguay. Las politicas de inclusión social para personas LGBT del Ministerio de Desarrollo Social (2010 - 2014). Informe final. Rocha, C. Montevideo: Ministerio de Desarrollo Social. Disponível em: https://uruguay.unfpa.org/sites/defaul t/files/pub-pdf/112_file1.pdf. Acesso em 20 de abril de 2020.

Ministerio de Desarrollo Social. (2013) Poli\#ticas pu\#blicas y diversidad sexual: ana\#lisis de la heteronormatividad en la vida de las personas y las instituciones. Informe final. Sempol, D. La renegociacio\#n del orden social: Cambios y permanências. Montevideo: Ministerio de Desarrollo Social. 7-22. Recuperado de: https://issuu.com/dnpsmides/docs/pol_ticas_p_ _blicas_y_diversidad_s. Acesso em: 20 de abril de 2020. 
Ministerio de Desarrollo Social-Administración Nacional Educación Pública (2019). Convivencia y discriminación en Centros de Educación Media en Uruguay. Documento conceptual metodológico. Montevideo: MIDES. Recuperado de: https://www.gub.uy/ministerio-desarrollo-social/sites/ministerio-de sarrollo-social/files/documentos/publicaciones/Convivencia\%20y\%20d iscriminaci\%C3\%B3n\%20en\%20\%20Centros\%20de\%20Educaci\%C3\% B3n\%20Media\%20en\%20Uruguay.pdf >. Acesso em: 5 de out. 2020.

Moehlecke, S. (2009). As políticas de diversidade na educação no Governo Lula. Cadernos de Pesquisa, 39(137), 461-487.

Montevideo Portal. (2017). Se busca influir con la ideología del género: Sturla contra manual de educación sexual. Recuperado de: http://www.montevideo.com.uy/Noticias/-Se-busca-influir-con-la-i deologia-del-genero-Sturla-contra-manual-de-educacion-sexual-uc35020 5>. Acesso em: 28 jul. 2017.

Nascimento, T. B.; Castro, F. B. (2016). O ensino da dança nas aulas de educação física escolar e a compreensão dos meninos. Revista Biometriz, 10 (1), 1-15.

Ovejas Negras. (2016). Encuesta nacional de clima escolar en Uruguay 2016: Experiencias de niños, niñas y adolescentes lesbianas, gays, bisexuales y trans en establecimientos educativos. Montevideo: Ovejas Negras. Recuperado de: https://ovejasnegras.org/wp-content/uploads/2019/08/ENCUEST A-NACIONAL-DE-CLIMA-ESCOLAR-EN-URUGUAY-2016-VER SION-FINAL-DIC.2016-1.pdf>, Acesso em: 5 out. 2020.

Perez Riedel, M.; Scharagrodsky, P. (2020). Transgender youth and education in Argentina. In: Antagonizing White Feminism. Intersectionality's Critique of Women's Studies and the Academy. Edited by Noelle Chaddock and Beth Hinderliter. Maryland: Lexington Books. 83-104.

PCN Educação física Brasil. (1997). Secretaria de Educação Fundamental. Parâmetros curriculares nacionais: Educação física / Secretaria de Educação Fundamental. - Brasília: MEC/SEF, 1997. 96p. Recuperado de: http:// portal.mec.gov.br/seb/arquivos/pdf/livro07.pdf >. Acesso em: 15 de abril de 2020.

Parâmetros Curriculares Nacionais: introdução aos parâmetros curriculares nacionais (1997)/ Secretaria de Educação Fundamental. - Brasília: MEC/ SEF. 126 p. Recuperado de: http://portal.mec.gov.br/seb/arquivos/pdf/l ivro01.pdf. Acesso em: 10 de abril de 2020.

Parâmetros Curriculares Nacionais: Educação Física (1998) Secretaria de Educação Fundamental. Brasília: MEC / SEF, 1998. 114 p. Recuperado de: http://portal.mec.gov.br/seb/arquivos/pdf/fisica.pdf >. Acesso em: 13 de abril de 2020.

Real de Azúa, C. (1964). El impulso y su freno: tres décadas de Batllismo y las raices de la crisis uruguaya. Montevideo: Ediciones de la Banda Oriental.

Rohden, F.; Carrara, S. (2008). O percurso da experiência gênero e diversidade na escola: pretensões, realizações e impasses. In: ROHDEN, F., ARAÚJO, L.; BARRETO, A. (Orgs.). Os desafios da transversalidade em uma experiência de formação on line: Curso Gênero e Diversidade na Escola. Rio de Janeiro: Cepesc.

Rueda, A. (2018). La Educación Sexual Integral: indagaciones desde las agendas travestis trans. Mora. $\mathrm{n}^{\circ} 25$. 
Saraiva, M. C. (1999) Co-educação Física e Esportes: quando a diferença é mito. Ijui: Unijui, v. 1.208 p.

Scharagrodsky, P. (2019). Trans-formando el espacio educativo y deportivo. El caso de la comunidad trans en la capital argentina. Revista Investiga +, Año. 2, n. 2. 15-35.

Souza Júnior, O.; Darido, S. C. (2002). A prática do futebol feminino no ensino fundamental. Motriz, 8 (1), 1-9.

Schenck, M. (2014). Con la violencia heteronormativa en el armario: el desafito de visibilizar formas naturalizadas de discriminacio\#n en el a\#mbito educativo en silencios y otras violencias. Poli\#ticas pu\#blicas, regulaciones discriminatorias y diversidad sexual. Informe final. p. 89-119. Montevideo: Mides. Recuperado de: http://ovejasnegras.org/es/wpcontent/uploads/2 016/07/Libro_Diversidad_sexual_V_1.pdf $>$. Acesso: em 25 de julho de 2018.

Secretaria de Derechos Humanos de la Provincia de Buenos Aires. (2019). Primer relevamiento sobre condiciones de vida de la población trans/travesti de la Provincia de Buenos Aires.

Sempol, D. (2013). La renegociacio\#n del orden social: Cambios y permanências. In: Ministerio de desarrollo social. Poli\#ticas pu\#blicas y diversidad sexual: ana\#lisis de la heteronormatividad en la vida de las personas y las instituciones. Informe final. Montevideo: Ministerio de desarrollo social. 7-22.

Silva, E. M. da; Ferreira, E. B. (2019). Os movimentos das professoras da educação básica na constituição das políticas de gênero na escola. Educ. Pesqui. São Paulo, v. 45, p. 200 -235. Recuperado de: . Epub Sep 16, 2019. https://doi.org/10.1590/s1678-4634201945200235>. Acesso em: 27 Apr. 2020.

Vianna, C. P.; Unbehaum, S. (2006). Gênero na educação básica: quem se importa? Uma análise de documentos de políticas públicas no Brasil. Educação e Sociedade, 27 (95), 407-428.

Vianna, C. P.; Unbehaum, S. (2016). Contribuições da produção acadêmica sobre gênero nas políticas educacionais: elementos para repensar a agenda. In: Carreira, Denise ... et al. Gênero e educação: fortalecendo uma agenda para as politicas educacionais. São Paulo: Ação Educativa, Cladem, Ecos, Geledés, Fundação Carlos Chagas.

\section{Notas}

1 No Brasil, em que pese algumas políticas de gênero terem se iniciado no governo de Fernando Henrique Cardoso (1995-2003) foi nos governos de Luiz Inácio Lula da Silva (2003-2011) e de Dilma Vana Rousseff (2011-2016) que houve um impulsionamento de políticas públicas e sociais de gênero para a educação. No Uruguai, apesar de que nos anos 90 se vivenciou um processo em que se colocaram os temas de gênero, diversidade sexual e educação sexual na agenda política, foi a partir de 2005, depois da esquerda chegar ao poder, que se obtiveram importantes conquistas de leis por meio do poder legislativo, e nas políticas públicas de gênero, diversidade sexual e educação sexual para a educação. $\mathrm{Na}$ Argentina o processo foi mais localizado, embora com resistências e não linear, nas últimas duas décadas com mudanças mais profundas de ordem legislativa, com criação de Leis e Lineamentos 
Curriculares (2008), o que permitiu uma posterior produção de material didático e formação docente.

2 Termo apresentado por Stephen Ball em entrevista concedida a Mainardes e Marcondes (2009) que expressa a dinâmica de efetivação de uma política pública que ganha contornos diferenciados desde a sua proposição até a sua execução.

3 Madsen (2008) denomina de Agenda internacional de gênero “[...] o conjunto de entendimentos e princípios sobre a promoção da igualdade de gênero na educação [...]" (p. 57), ou seja, documentos elaborados no âmbito da Organização das Nações Unidas (ONU) com o objetivo de promover os direitos das mulheres, posteriormente assimilados em documentos internacionais de educação, tanto na ONU como em organismos multilaterais, como o Banco Mundial.

4 Sobre co-educação, ver Saraiva (1999) e Auad (1999).

5 Entendemos ser possível prolongar esse período até 2016, antes do golpe jurídico parlamentar que atingiu o governo de Dilma Rousseff.

6 Em 2002, ainda na estrutura do Ministério de Justiça, foi criada a Secretaria Nacional dos Direitos da Mulher. No ano seguinte, passou para uma nova configuração, denominada de SPM, vinculada diretamente à Presidência da República, com estatuto de ministério, contando, em sua composição, com representantes da sociedade civil e do governo.

7 Tipo de política que amplia os canais de diálogo da sociedade civil com os governos, por meio da participação em fóruns, seminários e conferências, dentre outros, principalmente dos movimentos sociais (Moehlecke, 2009).

8 Essa política propunha promover uma cultura do respeito e a garantia de direitos humanos, da equidade étnico-racial e de gênero, da valorização da diversidade (BRASIL/MINISTÉRIO DA EDUCAÇĀO/SECRETARIA DE CONTINUADA, ALFABETIZAÇÃO, DIVERSIDADE E INCLUSÃO, 2015) e buscava atuar transversalmente na institucionalidade.

9 A experiência de implementação do curso GDE envolveu parcerias com as universidades federais e estaduais, por meio de seus núcleos de estudos sobre gênero e sexualidade ou professoras estudiosas da temática. $\mathrm{O}$ curso foi ofertado aos/às profissionais da educação das redes públicas estaduais e municipais de ensino de todas as unidades federativas do país. Segundo dados da SPM/PR (2012), o GDE havia sido ofertado por 38 universidades públicas estaduais e federais, atingindo mais de 40 mil profissionais da educação, nas modalidades aperfeiçoamento e especialização.

10 Podemos citar também o Plano Plurianual 2012-2015 - o Plano Mais Brasil.

11 Alguns desses cursos traziam a discussão de gênero em seus cadernos, como foi o caso dos cursos Educação em Direitos Humanos (EDH), Gestão de Políticas Públicas em Gênero e Raça (GPPGer) e Educação para a diversidade (EDC), ofertados pela Universidade Federal do Espírito Santo (UFES) no período de 2009-2014.

12 Principalmente no que tange ao debate sobre identidade de gênero e orientação sexual.

13 Em 2016, com o governo do presidente Michel Temer, a SECADI foi extinta (BRASIL, 2017). O atual governo do presidente, Jair Bolsonaro, em 2019, manteve a extinção.

14 Esse projeto (PL no $1.411 / 2015$ e PL $n^{\circ} 867 / 2015$ ) se relaciona com um movimento político de direita, conservador e, principalmente, privatista, que se aprofunda e busca afetar frontalmente a educação nacional, propondo, como princípios, a neutralidade política, ideológica e religiosa; e acusa os/ as professores/as de exercerem uma doutrinação sobre as crianças e os adolescentes.

15 Lei n 26.743, que dispõe sobre a identidade de gênero (2012).

16 A gestão Cambiamos governou a Argentina entre 2015-2019. Durante seu mandato, os indicadores de pobreza, indigência, desigualdade, desemprego e precarização laboral aumentaram fortemente. No plano educativo, entre 
2016 e 2018, o investimento nesta pasta caiu 9\%, em termos reais, e o poder aquisitivo do salário docente caiu $14 \%$ entre 2015 e 2018 , com fortes disparidades entre os estados.

17 Lei sobre Saúde Sexual e Procriação Responsável no 2.5673 (2002); Lei Nacional de Proteção integral dos Direitos de Meninos, Meninas e Adolescentes nº 26.061 (2005); Convenção sobre os Direitos das Pessoas com Discapacidade (2006); Lei de Prevenção e Sanção do Cuidado de Pessoas e Assistência a suas Vítimas, no 26.364 (2008); Lei de Proteção Integral para Prevenir, Sancionar e Erradicar a Violência contra as Mulheres, no 26.485 (2009); Lei Matrimônio Igualitário, no 26.618 (2010), modificação do Código Civil e Lei de Identidade de Gênero, no 26.743 (2012). No campo educativo: a modificação do artículo $1^{\circ}$ da Lei 25.808 (proibição em estabelecimentos de educação pública de impedir a continuação normal dos estudos a alunas grávidas ou a mães em período de gestação (2003); o Programa Nacional de Educação Sexual Integral - Lei nº 26.150 (2006); Lei de Educação Nacional, n 26.206 (2006) e os Lineamentos Curriculares para a Educação Sexual Integral (2008). Isso permitiu que, entre 2009 e 2010, fossem desenhados e distribuídos distintos materiais educativos em todas as jurisdições do país e se capacitaram, a partir de 2012, os/as docentes em boa parte dos estados argentinos.

18 Entre seus objetivos foram destacados: 1. Incorporar a educação sexual integral dentro das propostas educativas orientadas à formação harmônica equilibrada y permanente das pessoas. 2. Assegurar a transmissão de conhecimentos pertinentes, precisos e confiáveis e atualizados sobre os distintos aspectos involucrados na educação sexual integral. 3. Promover atitudes responsáveis ante a sexualidade. 4. Prevenir os problemas relacionados com a saúde em geral e a saúde sexual e reprodutiva em particular. 5. Procurar igualdade de trato e oportunidades para mulheres e homens.

19 Argentina. Ministerio de Educación de la Nación. (2012a). Serie Cuadernos da ESI. Educación sexual integral para la educación secundaria II: contenidos y propuestas para el aula. Disponível em: http://www.bnm.me.gov.ar/giga 1/do cumentos/EL005009.pdf. Acesso em: 20 mar. 2019.

20 Argentina. Ministerio de Educación de la Nación. (2012b). Serie Cuadernos da ESI. Educación sexual integral para la educación secundaria II: contenidos y propuestas para el aula. Disponível em: http://www.bnm.me.gov.ar/giga 1/do cumentos/EL005009.pdf. Acesso em: 20 mar. 2019.

21 Com uma média de vida que não supera os 35 a 40 anos e uma altíssima porcentagem de sua população em situação de vulnerabilidade social, cultural e política, os distintos informes, etc.- sobre o heterogêneo coletivo trans realizados nas últimas duas décadas em CABA e em distintos estados da Argentina, tem identificado o âmbito educativo como compulsivamente excludente e estruturalmente violento (Berkins; Fernández, 2005; Berkins, 2007). Também ver: Argentina. Ministerio Público de la Defensa de la Ciudad Autónoma de Buenos Aires. (2017). La revolución de las mariposas. A diez años de la Gesta del Nombre Propio. Disponível em: https://www.mpdefensa.gob.ar/publicaciones/la-revolucion -las-mariposas-a-diez-anos-la-gesta-del-nombre-propio. Acesso em: 1 mar. 2018. Argentina. Secretaria de Derechos Humanos de la Provincia de Buenos Aires. (2019). Primer relevamiento sobre condiciones de vida de la población trans/travesti de la provincia de Buenos Aires.

22 Como são: a Lei de Oito Horas de Trabalho (1915); Lei do Voto Feminino (promulgada em 1932, mas que entrou em vigor somente em março de 1938, pela interferência do golpe de estado de Terra, no ano 1933); Lei contra o Racismo, a Xenofobia e Toda Outra Forma de Discriminação (2004); Lei de União Concubinária (2007), que regulamentou a união estável de todos os casais, incluindo os do mesmo sexo biológico; a Lei de Direito à Saúde Sexual e Reprodutiva (aprovada em 2008, e regulamentada em 2010), que inclui elementos relacionados com a diversidade sexual e a não discriminação; 
Lei de Identidade de Gênero (2009); Lei de Adoção por Pessoas do Mesmo Sexo Biológico (2009); Lei de Aborto Legal (2012); Lei no 19.076; Lei de Matrimônio Igualitário (2013); Lei de Regulamentação da Maconha (2013).

23 O CODICEN cria, em 2005, uma comissão com o objetivo de elaborar um projeto de educação sexual para a educação pública uruguaia.

24 Instituto Nacional das Mulheres (INMUJERES-MIDES), dependente do Ministério de Desenvolvimento Social, Uruguai, 2005.

25 É o órgão da Administração Nacional de Educação Pública com o cargo de promover a educação inicial e primária no país.

26 É uma organização social no Uruguai, que defende a diversidade sexual e promove os direitos das pessoas LGBTI.

27 Organização não governamental da sociedade civil comprometida na defesa dos Direitos Humanos de crianças e adolescentes, Uruguai.

28 A Lei no 18.246 (2007), de União Concubinária, reconhece os casais do mesmo sexo; a modificação de disposições referidas à adoção, protegendo e igualando os direitos dos filhos e filhas das famílias LGBTIQ, que permite a adoção conjunta por parte de casais em união concubinária por meio da Lei $n^{\circ} 18.590$ (2009); O Código da Criança e do Adolescência; a Lei $n^{\circ}$ 18.620 (2009) de Direito à Identidade de Gênero e à Mudança do Nome Social em documentos identificatórios, permite à população trans obter um documento de acordo com sua identidade de gênero; a Lei no 19.076 (2013), de Matrimônio Igualitário, reconhece o direito dos casais do mesmo sexo a contrair matrimônio em igualdade de condições que os casais heterossexuais (Rocha, 2014).

29 Que tem o nome de "Propuesta didáctica para el abordaje de la educación sexual en Educación Inicial y Primaria”, elaborada em conjunto entre o Fundo de População das Nações Unidas (UNFPA), a ONG Gurises Unidos e o Conselho de Educação Inicial e Primária (CEIP), publicada em 2017 (GURISES UNIDOS, 2017). 